\title{
Psychology in an Indeterminate World
}

\section{Ludger van Dijk}

Centre for Philosophical Psychology, Department of Philosophy, University of Antwerp
Perspectives on Psychological Science

$1-13$

(C) The Author(s) 2021

(c) (i) (5)

Article reuse guidelines: sagepub.com/journals-permissions DOI: $10.1177 / 1745691620958005$ www.psychologicalscience.org/PPS

@SAGE

\begin{abstract}
By sharing their world, humans and other animals sustain each other. Their world gets determined over time as generations of animals act in it. Current approaches to psychological science, by contrast, start from the assumption that the world is already determined before an animal's activity. These approaches seem more concerned with uncertainty about the world than with the practical indeterminacies of the world humans and nonhuman animals experience. As human activity is making life increasingly hard for other animals, this preoccupation becomes difficult to accept. This article introduces an ecological approach to psychology to develop a view that centralizes the indeterminacies of a shared world. Specifically, it develops an open-ended notion of "affordances," the possibilities for action offered by the environment. Affordances are processes in which (a) the material world invites individual animals to participate, while (b) participation concurrently continues the material world in a particular way. From this point of view, species codetermine the world together. Several empirical and methodological implications of this view on affordances are explored. The article ends with an explanation of how an ecological perspective brings responsibility for the shared world to the heart of psychological science.
\end{abstract}

\section{Keywords}

affordances, ecological psychology, environment, indeterminacy, perception, uncertainty

But choice is not arbitrary, not in a universe like this one, a world which is not finished and which has not consistently made up its mind where it is going and what it is going to do.

$$
\text { -John Dewey (1958, p. 76) }
$$

The world has been infused with life for millions of years, from the soil we stand on to the food we eat. To this very day the world and its inhabitants take shape together. Think for instance of vultures living close to villages in India. These vultures have been able to live there for generations by feeding on dead cattle left by humans. By eating cattle the vultures in turn keep disease from spreading and thus help to make the village habitable (Houston \& Cooper, 1975). These different species, human and nonhuman, depend on each other by codetermining the world, which is to say that they actively maintain a precarious stability across generations.

On the face of it, psychological science seems perfectly positioned to do justice to the precariousness of life in a shared world. From probabilistic models of cognition to predictive-processing accounts, representational approaches to psychology centralize the uncertainty that comes with a changing world (e.g., Courville,
Daw, \& Touretzky, 2006; Friston, 2009; Ma, 2012). Perception involves inferring from sensory patterns the parameters of a generative model that can predict the real world. Perceiving animals "assume" that sensory patterns should be attributed to a set of "unobservable 'latent' causes" (Courville et al., 2006, p. 296). Uncertainty mounts as the model parameters fail to keep up with a rapidly changing world.

On second thought, however, being uncertain about the world as it changes does not mean that the world itself is uncertain. Taking the world to be a (hidden) cause of stimulation suggests a view according to which, at any point in time, the world is in a definite state. This state is usually considered to be determined by (physical) laws before action. The representational models are thus built in the hope of recovering this lawfully determined structure (Von Helmholtz, 1878, Chapter 4). It is not the world that is uncertain. It is rather we who are uncertain about the world.

\section{Corresponding Author:}

Ludger van Dijk, Centre for Philosophical Psychology, Department of Philosophy, University of Antwerp

E-mail: ludger.vandijk@uantwerpen.be 
The vultures in India suggest a different picture of the world we live in. A world infused with life is not fully determinate at any point in time but is instead determining over time. Is the carcass all right to eat? Will it afford nourishing the impatiently waiting vulture chick? Will the village enable human organisms to raise children, perhaps one day becoming cattle farmers? Being sensitive to these possibilities for action (i.e., these "affordances"; Gibson, 1966, 1979) is crucial if animals are to get by in a shared world.

Yet such affordances depend, in part, on a contingent history of generations of active animals and, moreover, on successfully continuing their activities together in the future. For example, when humans started treating their cattle with diclofenac, a painkiller highly toxic to vultures, the vultures' way of life quickly became impossible (Green et al., 2004). Stability thus breaks down, and the people in turn need to find ways to dissociate their lives from the lives of the vultures if life in the village is to continue (Van Dooren, 2014). The main question this article aims to answer is how to equip psychological science with a perspective that captures the precariousness of life in a world that animals determine together.

The difficulty of capturing the indeterminacy of this world sparks a second concern. There seems to be a root mismatch between thinking that the world is actively determining across generations of different species and a perspective that requires the world to be determined in advance of activity, ready to stimulate the senses. By relegating the indeterminacies of the shared world of vultures, humans, and cattle to uncertainty in their respective mental models, attention is shifted away from the real and everyday difficulties these animals have to cope with (Dewey, 1958; Van Dijk, 2020). But a shared world is in need of participation, maintenance, and care. The concern, then, is that representational psychology cannot foreground the role humans play in maintaining a place for other animals.

The main aim of this article is thus to provide psychology with a new perspective that emphasizes the precarious stabilities of a shared world. Ecological psychology, with its concept of affordance, will be introduced as a means of obtaining this perspective. The use of the ecological approach has so far been largely limited to perception and action dynamics (e.g., Turvey, 1990; Warren, 2006). However, its empirical successes grow out of a much more encompassing change in perspective on psychology, according to which animals experience the world as they actively participate in it. The world is not a prior cause of an inner experience. It is this perspective that warrants a closer look.

This article situates the ecological approach in the context of evolutionary and early pragmatist thinking.
It proceeds to show how ecological theory understands experience as being a world-involving activity. I argue that the affording world should be considered in temporally reciprocal terms: Affordances are open-ended processes that concurrently give shape to the material world of a species as well as the individual animal's surroundings. This notion of affordances helps us to gain sight of the large-scale material organizations of human activities. I then introduce several empirical methods at ecological psychology's disposal and propose ways of expanding their range. The article ends with an explanation of how this ecological perspective brings responsibility for the shared world to the very heart of psychological science.

\section{A Primer on Ecological Psychology}

Humans were long thought to stand apart from the animal kingdom. Indeed, they were thought to be unique in being endowed with the cognitive equipment to reason about the world. Think of the works of 19thcentury physiologist Hermann von Helmholtz, a main antecedent of many modern theories of mind (Clark, 2016; Friston, 2009; Ma, 2012; for critiques, see Bruineberg, Kiverstein, \& Rietveld, 2018; Heft, 2001; Turvey, 2019). In Helmholtz's view, perception is tasked primarily with building an accurate model of the underlying structure of reality. These models allow reasoning about the world and hypothesize how one's movements may affect it. Such a take on perception is distinctively pre-Darwinian.

By contrast, Darwin's theory of the evolutionary ecology of animals placed humans inside a biological process of growth and development. This view centralized variability and chance. Evolutionary processes branch off in multiple directions; they are precarious and full of dead ends. They are, in a word, open-ended. Accordingly, perception is not about gaining access to an objective world, as it was there all along. Instead, perception develops to coordinate with and adjust to changing worldly conditions (Chemero, 2009; Gibson, 1979; Myin, 2016). Although we can, at least cosmetically, adjust the Helmholtzian perspective to include evolutionary considerations, Darwin suggested a much more radical break with this anthropocentric view (Barrett, 2011; Reed, 1996).

On the Origin of Species was published in 1858 and started to gain traction several decades later. In its wake, a new wave of theorizing developed in philosophy (e.g., American pragmatism; Dewey, 1910/2009; James, 1912; Mead, 1912) and in psychology (e.g., Gestalt psychology and behaviorism). The ecological approach to psychology, pioneered by James Gibson, grew out of these developments (Gibson, 1966, 1979; 
see Chemero, 2009; Costall, 2004; Heft, 2001, 2007; Reed, 1996). This section introduces its main characteristics to develop a notion of affordances that befits an indeterminate world.

\section{Animal-environment systems}

The ecological perspective can be summarized as involving three interrelated characteristics. First, it starts from the assertion that the animal and the environment, which are reciprocally dependent on one another, make an "inseparable pair" (Costall, 2004; Gibson, 1979, p. 8; Heft, 2007; Turvey \& Shaw, 1999; Warren, 2006). It is in the coordinative activities that maintain their mutual fit that the animal and the world continuously take shape. They form, in other words, an animal-environment system.

Starting from an animal-environment system leads to a second assertion. The ecological approach implies that perception is not representational but rather relational in nature (Chemero, 2009; Costall, 1995, 2004; Dent-Read \& Zukow-Goldring, 1997; Gibson, 1979; Heft, 1989, 2001; Heras-Escribano, 2019; Rietveld \& Kiverstein, 2014; Stoffregen, 2003; Szokolszky \& Read, 2018). The world is a constituent of experience-not a cause of it (Gibson, 1979, p. 239; see Heft, 1989, 2001; Noble, 1981; Shotter, 1983; Van Dijk \& Rietveld, 2018). It is this relational conception of mind that undercuts the need for unconscious inference or other mental mechanisms that manipulate content about the world. In ecological psychology, perception is therefore said to be direct (e.g., Chemero, 2009; Michaels \& Carello, 1981; Turvey, 1992).

Third, in keeping with the Darwinian outlook, the world taking shape within the system is considered in pragmatic terms. Think back to the vultures in India. What vultures need to sense is, for instance, whether a carcass would nourish the vulture's chick or whether a ledge affords a base of support for landing or building a nest. The vulture experiences the world as pragmatically significant or meaningful, as edible, "perch-able"it "affords" all of these things to the vulture. Gibson coined the term affordance for these possibilities for action offered by the environment (Gibson, 1966, 1979). Affordances cast the world pragmatically to emphasize that the world is experienced for the practical differences it can make throughout an animal's life.

Early studies on affordances revealed how perception is scaled to action, so that, for example, we perceive stairs as climbable (Mark, 1987; Warren, 1984), objects as reachable (Carello, Grosofsky, Reichel, Solomon, \& Turvey, 1989), and so on. But affordances have been shown to change across development and learning (Heft, 1989). Depending on their locomotor ability, toddlers will differ in how they perceive a sloping surface
(Adolph, Eppler, \& Gibson, 1993), whereas for skilled climbers even ice walls may afford a path to the top (Seifert et al., 2014). Social cooperation further changes our possibilities for action (Richardson, Marsh, \& Baron, 2007), and in adapting to social practices affordances seamlessly incorporate values and norms (Costall, 1995, 1997; Heft, 2007; Hodges \& Baron, 1992). They account for the ability to adopt a different style for carrying an infant than for carrying, say, a bag of groceries (Hodges \& Lindhiem, 2006) and for acquiring a sense of how to break appropriately for a red light with or without a passenger (Fajen, 2007).

Ecological psychology developed dedicated empirical methods in line with these three commitments. Its methodology was aptly summarized by Bill Mace as to "ask not what's inside your head, but what your head's inside of" (Mace, 1977, p. 43). It favors the study of "natural" tasks and focuses on the worldly structure (i.e., "information") that enables performance (e.g., Lee \& Reddish, 1981; Warren, Kay, Zosh, Duchon, \& Sahuc, 2001). It emphasizes the multiscaled processes in which such performance is situated and develops nonlinear models of coordination dynamics to explain and predict behavior (e.g., Chemero, 2009; Kelso, 1995; Kugler \& Turvey, 1987; Schmidt \& Richardson, 2008). The development of the notion of affordances occupies most of this article, but I return to ecological psychology's methods later and consider how a notion of affordances that centralizes indeterminacy allows us to expand on these methods.

\section{Getting abead of ourselves}

To anticipate the main argument for an open-ended notion of affordances, it is useful to examine how the animal-environment system develops with experience through the lens of pragmatist John Dewey. Dewey has had a lasting influence on the ecological approach (Gibson, 1966; see also Costall, 1995; Heft, 1989; Ingold, 2018; Noble, 1981; Shaw \& Turvey, 1981). His view of experience was introduced to ecological psychology by William Noble and John Shotter (Noble, 1981; Shotter, 1983). Consider Dewey's analysis of a child burning herself on a flame (Dewey, 1896). Traditionally, the event is thought to partition into a flame being first a stimulus followed by a reach in response to it. The reach causes a painful burn, which is another stimulus that causes a withdrawing response. However, for Dewey, this story of causes and effects ignored the developmental question that he felt a theory of psychology should answer: Why is the flame a "stimulus" in the first place?

Dewey asserted that the event of burning a finger starts within an animal-environment system amid ongoing coordinated activity: "The real beginning," he wrote, "is with the act of seeing; it is looking and not the 
sensation of light" (Dewey, 1896, pp. 358-359). Burning a finger is not connected by an internal mental process to the sensation of light, but it is an ongoing development of the activity of experiencing the light. Over the course of the child's activity, undergoing the painful burn develops the act of seeing a light into the "seeingof-a-light-that-means-pain-when-contact-occurs" (Dewey, 1896, p. 360).

In Dewey's analysis we thus find a reciprocity that is not limited to the relation between the worldly stimulus and the child's response. A second reciprocity emerges across two timescales. Stimulus and response are small yet extensive processes unfolding within a larger scale coordinative activity. Neither the two smaller scale processes nor this larger scale coordinative activity is fully determinate at a single point in time. They rather codetermine over time. That is, the stimulus develops as the response develops (Shotter, 1983). In fact, by responding, the child's activity is not only determining the stimulus but also concurrently determining the much larger scale of activity out of which the stimulus and response emerge. It is for this reason that, for Dewey, withdrawing the hand was a response "not merely to the stimulus; it is into it" (Dewey, 1896, p. 359).

To make sense of this perhaps cryptic remark, we can think of the developmental process Dewey describes as a temporally reciprocal process. A "temporal reciprocity" is a relational process in which at least two relata concurrently take shape over different timescales (Van Dijk, 2020). Dewey describes a temporally reciprocal process because (a) the coordinative activity enables the light to matter, and the burn to hurt, while (b) the light and the burn achieve continuation of the child's coordinative activity with the world in a particular way.

The ecological approach took perception to be direct-it did not require mental inferences or manipulation of content about the world. The mind was said to be relational in nature. The temporal view that runs from evolutionary theory via Dewey to the ecological approach suggests that we can understand this as the claim that experience is an ongoing process of coordination with the world. The extensive, material-determining process is aiming for a light, it is searching for food. As a temporal reciprocity, the process is continuously getting ahead of itself: It is not directed toward a definite state, but it does exhibit directionality (Dewey, 1896; Heft, 1989; James, 1912; Ingold, 2015; Shotter, 1983; Van Dijk \& Rietveld, 2018).

\section{An Ontogeny of Affordances}

Dewey's analysis showed how affordances emerge across development in an animal-environment system. As a temporal reciprocity the system gets ahead of itself by continuously extending into new processes. The coordinative activity of children sets them up to be invited by a light to reach for it (Shotter, 1983). That is, the world-involving history of an animal forms the terms in which materials now enter into a relation with the animal. Being burned by the flame concurrently develops the child's activity (to now be receptive to flames as pain when contact occurs). Across development, flames afford a painful burn to the child (Heft, 1989). Affordances emerge across development. However, although this view has "an admirable pedigree," with Dewey as its main proponent, it seems not to be the whole story (Reed, 1996, p. 26). Do we really want to claim that a flame affords pain only after someone has been burned?

\section{Two views of affordances}

Affordances have been used to articulate two distinct intuitions. On the one hand, affordances adhere to an individual animal's lived experience of the material world. Water, for example, will be seen to afford drinking; it might "invite" me to drink when I am thirsty. Koffka and other Gestalt psychologists focused on this idea when asserting that the world has a "demand character" for an animal (see Gibson, 1966, p. 274, 1979, p. 128). In this vein, and following the phenomenological analysis of Dreyfus and Kelly (2007), affordances have been said to have an "invitational" character relative to an individual (Rietveld \& Kiverstein, 2014; Withagen, De Poel, Araújo, \& Pepping, 2012; see Costall, 1995, p. 471).

Although this animal-relative conception allows for individual differences in perception, and for changing affordances with new skills (Franchak \& Adolph, 2007; Heft, 1989; Withagen \& Van Wermeskerken, 2009), there is also a sense in which an affordance is simply there for everyone to find (Chemero, 2003; Gibson, 1979, p. 129; Reed, 1996; Turvey, 1992). Water affords drinking whether I am thirsty or not. The drinkability is not supposed to depend on any single animal's relation with the water (Chemero, 2003; Rietveld \& Kiverstein, 2014; Stoffregen, 2003). One way of doing justice to this view has been to define affordances in relation to a population or species of animal: Whereas water affords drinking to humans it does not, say, to a frog (which in fact takes up water solely through the skin).

In an effort to retain both of these intuitions, several authors have proposed incorporating them into one single concept. Harry Heft, for example, distinguishes between affordances as "potential" relations and as relations actualized by an individual (Heft, 1989, 2001, p. 133; see also Ben-Zeev, 1984). Edward Reed, who sought to tie affordances to the evolutionary process, proposed that affordances should be understood as 
resources for a species or population (Reed, 1996). These resources are "realized" by individual animals as relations with their surroundings (Reed, 1996, p. 26; see, e.g., Gibson, 1979, p. 129). Proposals inspired by Heft or Reed are reflected, for example, in the distinction Rietveld and Kiverstein (2014) make between a landscape of affordances that belongs to a "form of life" (e.g., a species) and a field of relevant affordances belonging to an individual. They are also reflected in the distinction Baggs and Chemero (2018) make between affordances as "dispositional properties" belonging to the habitat of a species and as features of the Umwelt of an animal.

Having both an individual and species-relative conception makes affordances well suited for focusing on the stabilities of the world: the material resources that are reliably available across generations and the immediate relevance of the individual's surroundings. Few conceptions, however, have attempted to foreground their more indeterminate, open-ended character. To do so, the reciprocal dependence between affordances for a species and those for an individual would need to be explored. However, although the process of how an individual learns to realize or actualize affordances is well studied, ecological psychologists have been reluctant to explore the converse relation: how affordances may depend on the activities of animals. Reed, for example, went so far as to deny this converse relation even existed (Reed, 1996, pp. 26-27; see Costall, 1999).

There are cases, such as the affordance of a flame to hurt, that hold across species. The overwhelming majority of affordances, however, have a more conditional and indeterminate character. Even the drinkability of water is precarious in everyday life, as is the effect of painkillers on vultures already suggested. The assertion of an affordance ready to be discovered implies processes in which such availability is maintained (Costall, 1995). To clarify the nature of the indeterminacy that comes along with this process, we need to explore the reciprocal relation between the speciesand individual-relative notion of affordance.

\section{Affordances as process}

Dewey's analysis of stimulus-response theory and the temporal reciprocity derived from it suggests that there are actually two notions of reciprocity between which we should distinguish. Think of a process of interaction. For instance, the world impinges on the senses, causing sensory patterns that change a mental model (which predicts how movements would affect the world). Here, there are first two discernable entities, a world and a model, and these entities interact via movements in the world so that each changes dynamically with every successive iteration. At each point in time, however, these entities are in a determinate state. This state determinacy is, for instance, what allows for "uncertainty" to arise: The states of the model may no longer correspond to the present value of the states of the world (Courville et al., 2006).

A crucial insight from evolutionary theory, amplified by pragmatism and passed on to ecological psychology, is that the many phenomena of life are not like two discernable entities iteratively affecting each other's states. This is because these phenomena are not states determined independently of time. They are rather temporally constituted processes (Gallagher 2017; Kirchhoff, 2015; Van Dijk, 2020). Neither relata in such processes are fully formed at any point in time. Instead, they take shape together over time. Think of the relation between species and animals. Species and animals do not interact; that is, a species is not a determinate thing that causes an animal or vice versa (see Oyama, 2000). Animals and their species are rather processes that codetermine each other across different timescales. Species and animals are temporally reciprocal. So too, I argue, the world gains a temporally reciprocal structure as it gets infused with life.

Critical to this temporal view, I think, is Harry Heft's approach to affordances, which is rooted in the processual thinking of the pragmatist tradition (Heft, 1989, 2001). As potential structures, affordances belong to the ongoing "sociohistorical" structure of the world (Heft, 2001, pp. 134-135). The word potential for Heft denotes not a state but a process that has been taking shape and, by animals' partaking in the process, can continue to take shape in a certain direction (see Dewey, 1915, p. 344; Oyama, 2000, p. 55). Amplifying Heft's insight, the proposal here is that the two aspects of affordances, the invitations for an animal and the materials for a species, are reciprocally related over time: By partaking in affordances, animals concurrently strengthen, or change, the possible ways of using materials that are available to others.

Affordances describe the process by which invitations and materiality concurrently take shape. Affordances are then temporal reciprocities in that invitations and materials codetermine each other while also unfolding across different timescales. Specifically, (a) the material world invites individual animals to participate, while (b) responding to these invitations achieves continuation of the material world in a particular way. Affordances are processes of materials setting up the conditions for their own continuation by inviting animals to contribute their activity (see Shotter, 1983; Van Dijk \& Rietveld, 2018). 


\section{Precarious ecological timescales}

How would this process work? Let us start from the open-ended invitations by the material in process. For instance, a vulture might sense an opportunity for feeding when encountering dead cattle left outside a village. We might be tempted to say that carcasses either afford feeding or they do not. But I would suggest thinking of the carcasses as setting up the conditions that invite the vultures to try and nourish themselves by eating. Vultures eating cattle, as mentioned earlier, kept disease from spreading close to villages in India, and so the vultures enabled the people in these villages to live their lives. Working together, over time, the edge of a village starts to be continued as a feeding place for vultures.

As many vultures share this site at the edge of a village concurrently and across generations, over a phylogenetic timescale a distinct way of life takes shape that is tied to a material world. That is, in an extensive process of generations of animals perceiving and acting in concrete situations over time, a species is taking shape. A species is a "way of life" (Gibson, 1979, pp. 7, 128, 143; Rietveld \& Kiverstein, 2014; Van Dooren, 2014). These ways of life may well be characterized by a certain genetic resemblance across generations, morphological or anatomical features, or geographical range. Such proxies are very useful in studying, say, population dynamics or in aiding conservation efforts. But with the ecological approach these characterizations are quantifications derived from the way animals live (Gibson, 1979; Oyama, 2000).

Successfully nourishing themselves, the vultures might stick around and make a nearby rock face their home, letting themselves be invited, for instance, to make a nest there. As the vulture's way of life develops in coordination with the steady supply of cattle, a rock face, and so on, the discarded cattle is no longer just inviting to eat. As it invites repeatedly, the availability of dead cattle becomes coordinated with a recurrent pattern of behavior of these vultures, along with the behaviors of the farmers who leave the cattle. The cattle becomes a food source. Likewise, the rock becomes a nesting place for these vultures. The world gets produced and reproduced as material that feeds into a way of life that is maintained over larger timescales.

The world taking shape across these phylogenetic processes is determining over time; that is, it is openended. Over time a nesting place can be maintained by inviting vultures to nest there. It is the material that persists across temporal frames shorter than, say, geological or climatologic processes that also shape the rock but longer than any single animal's activity that the rock face is helping to continue. Likewise, tied in with recurrent patterns of behavior, as a source of food the dead cattle persist across timescales longer than the time it takes for any one carcass to be eaten or decay. Across a phylogenetic process, in which the lives of generations of vultures rely on the availability of dead cattle at the edge of town, the lives of the animal and the world concurrently take shape together. By being open-ended, the world that animals share is actively maintained.

Indeed, because the processes that constitute the reciprocity unfold across different timescales, the reciprocity keeps getting ahead of itself: The phylogenetic process sets up vultures to rely on the activities of humans that leave dead cattle at the edge of town. The invitational character of affordances is thus maintained. This shared worldly history forms the terms in which vultures are open to the world, inviting them to feed on the discarded carcasses to continue their form of life.

The downside to this openness is that such a world is also fundamentally exposed. The very open-endedness of affordances that allowed the vultures' way of life to emerge can also invite the activity that breaks it down (Van Dooren, 2014). For instance, until recently in the coevolution of humans and vultures there has not been a need to develop a sensitivity for a difference between carcasses that do or do not contain diclofenac (if that is even possible). Vultures simply rely on the human way of living to continue their way of living. Thus, they are invited to continue their way of life by carcasses laden with painkillers. The same affordances that set up the conditions for their own continuation, and furnish the possibility of life for these vultures, are also at risk of nullifying themselves.

Although the intergenerational sharing of affordances may stabilize them over phylogenetic timescales, affordances nonetheless remain exposed and, in the end, precarious. The open-endedness of affordances in short implies responsibility. In acting, animals hold open the affording world for other animals to continue their way of living. The place an animal's activity maintains for others defines its responsibility in the world. Humans have a special responsibility in this respect, as they have extended their activities far and wide.

\section{Organizing the world}

In an affording world of temporally reciprocal processes, things can be coordinated across space and time that were previously uncoordinated. As argued by Alan Costall, affordances for humans are constituted in a web of human practices (Costall, 1995, 1997). Human practices are intergenerational processes in which materials get organized and concurrently organize us. For instance, our practices have organized grocery stores that set up the condition to invite individuals who have learned how to act there to do the appropriate 
thing (see Heft, 2001, 2007; Hodges \& Baron, 1992; Rietveld, 2008). Many ecological theorists have worked to understand those practices that humans have developed and now maintain together as they engage with the world (Barker, 1968; Costall, 1997; Heft, 2007; Rietveld, 2008; Van Dijk \& Kiverstein, 2020).

Having organized our material surroundings, the temporal reciprocity identified above suggests that these materials concurrently organize our activities. By being taught to respond to some of the invitations of a grocery store and not to others, we actively contribute to a more or less determined practice that maintains a certain material organization. Indeed, there are all kinds of sanctions if we were to misbehave (from annoyed frowns to being arrested). Participating in the maintenance of the material organization of grocery stores thus actively contributes to the way one should act there. Learning, through doing, our practical place in an affording world is learning to sense what is expected of us, which is to experience that one acts appropriately.

In the human form of life these material organizations emerge as a timescale between ontogeny and phylogeny. Over the course of centuries the human form of life has refined the practices that organize materials in elaborate ways. The way language has infused human life would be a case in point (Cowley, 2011; Dutilh Novaes, 2013; Nomikou, Leonardi, Radkowska, Rączaszek-Leonardi, \& Rohlfing, 2017; Van den Herik, 2018). Or consider mathematics-it too can be approached as a materially organized, and institutionalized, practice (Lave, 1988; Zahidi \& Myin, 2016). Mathematical practices have been cultivated for millennia. Many children are educated to act in accordance with these practices in their institutionalized form. Children develop an acute sensitivity for what the materials afford in concrete situations, for example, learning to use certain signs and symbols in organized ways by sitting at a desk, turned to the teacher with pen and paper at the ready, and so on.

Mathematics at the same time organizes us. As an intergenerational material organization, mathematics sets up the conditions for its own continuation. The use of probability calculus in medical education is an interesting example. Knowing the chances of a test returning falsely positive or negative is hugely important for a correct diagnosis. Yet even after decades of schooling, humans, including physicians, are notoriously bad at estimating these kinds of probabilities (Casscells, Schoenberger, \& Graboys, 1978). However, carefully targeted training in probability calculus can improve a physician's performance (e.g., Brush, Lee, Sherbino, Taylor-Fishwick, \& Norman, 2019). Proponents of the ecological approach would describe this improvement by saying that physicians are learning to participate in a highly refined material organization, and they are invited to contribute to it. They learn to be organized by the materials. As a result of a history of engaging with the world they learn to "think Bayesian"; that is, they see their patient, in part, in statistical terms.

The details of such an ecological approach to mathematics are beyond the scope of this article. The point here is to show how the view approaches the phenomena and where it looks to understand them. An ecological approach would not assume that all animals have Bayesian models already up and running to make sense of even the simplest forms of worldly engagement. Thinking statistically lies in prolonged participation in constructing actual material models, for instance, using pen and paper. Feeling sure about one's judgment, or experiencing uncertainty, emerges by participating in these and similar material organizations. The ecological approach takes the use of models to be a phylogenetically and ontogenetically late refinement of such engagement. The models are not considered explanations of behavior as much as worldly behavior to be explained. To the benefit of the patient, the indeterminacies of the affording world enabled reorganization and continuing the world in a new way. Affordances do this by being open-ended, setting up the conditions to invite a modern physician to approach a patient in light of a mathematical practice.

\section{What Is the Head Inside of?}

In introducing the basics of the ecological approach, animal-environment systems, a constitutive role for the environment in experience, and the notion of affordances, I noted that these characteristics lead to a commitment in ecological psychology to asking what one's head is inside of (Mace, 1977). I suggested that the affording world in which animals live is temporally constituted. It gets determined over time as life infuses the world across multiple timescales. The world comes with many stable and reliable features, but it also comes with precariousness, risk, and indeterminacy. These latter features tend to be neglected. This article has attempted to address that neglect. What, then, would scientific psychology in an indeterminate world look like? Building on ecological psychology's empirical methods, I want to suggest ways of expanding their scope. This allows for raising a deeper issue of responsibility in psychological science.

\section{Ecological emphases}

Pre-Darwinian psychology treated the world as the assumed cause of stimulation, so that perception becomes a process of inferring that cause. As a result, research on perception and cognition has overwhelmingly focused on the internal (neural) machinery that 
underlies these mental mechanisms. A functioning nervous system is crucial for many animals to stay coordinated with the world (Keijzer, Van Duijn, \& Lyon, 2013). There is increasing interest within ecological theory in examining the role that the brain plays in facilitating this coordination (Anderson, 2014; De Wit, de Vries, van der Kamp, \& Withagen, 2017; see De Wit \& Withagen, 2019). However, in the ecological approach, analysis starts by looking at the world. The ecological approach, for instance, famously examines the patterns in ambient energy, light, sound, and so on that are available over time and that can make a difference in keeping one coordinated with one's surroundings (Gibson, 1966).

Ambient patterns are called "information" in ecological psychology (Chemero, 2009; Gibson, 1979; Turvey \& Shaw, 1999; for critical discussions, see Van Dijk \& Kiverstein, 2020; Withagen \& Van der Kamp, 2010). A paradigmatic example is "optic flow": As one walks forward, a continuous backward flow of optical patterning is generated. Animals, from gannets to humans, have been shown to be highly sensitive to such patterning (e.g., Lee \& Reddish, 1981; Warren et al., 2001). Ambient patterning specific to particular sets of circumstances has been shown to make a difference to activities ranging from catching fly balls (Postma, Lemmink, \& Zaal, 2018) and making haptic judgments (Streit, Shockley, \& Riley, 2007; Turvey, 1996) to auditory perception (Gaver, 1993; Gordon \& Rosenblum, 2004) and sensorysubstitution tasks (Lobo, Travieso, Jacobs, Rodger, \& Craig, 2018).

Thinking of affordances not as predetermined states available to an animal but as determining processes expands the scope of these analyses. Patterns need not specify an affording world in advance of action; they can also be thought to specify in action. This suggests the method can be used to consider a much wider range of ambient structuring (e.g., Chemero, 2009; Myin, 2016; Withagen \& Van der Kamp, 2010). For instance, it allows previously used patterns to codetermine the significance of the currently available ones (Van Dijk \& Kiverstein, 2020). Although it makes sense that animals will develop sensitivity to ambient patterns that are particularly useful, such as optic flow, we should not expect the animals that evolve and develop in an open-ended world to be narrowly sensitive to only the patterns specific to a predefined set of circumstances (Withagen \& Chemero, 2009).

The ambient patterns generated along the animalenvironment system, such as optic flow, are often concurrently used to maintain and refine that system. As we saw in Dewey's analysis of a child's development, these patterns allow animals to expand their relation with their surroundings over time. To explore the role of action in this process, the mathematics of dynamical systems theory has been a natural ally of the ecological approach (e.g., Kelso, 1995; Kugler \& Turvey, 1987; Van Orden, Holden, \& Turvey, 2003; Warren, 2006). Dynamical analyses allow for explanations of the behavior of nonlinear, nondecomposable living systems (Van Orden et al., 2003; see Silberstein \& Chemero, 2013). They have proven their value in developing predictive models of coordinative structures, ranging from finger motion (Kelso, 1995) to interpersonal coordination such as crew rowing (Cuijpers, Den Hartigh, Zaal, \& de Poel, 2019) or casual conversation (Richardson, Dale, \& Kirkham, 2007).

Dynamical systems deal particularly well with systems that self-organize across multiple timescales (Schmidt \& Richardson, 2008; Stepp \& Turvey, 2010; Warren, 2018). However, these analyses have largely been limited to the dynamics of action. The temporal constitution of affordances suggests that there is no principled reason not to approach the material organization of the world using similar methods. The notion of "circular causality," for instance, can capture how situated activity can be both enabled by the larger scale dynamics of the system and concurrently constrain those dynamics. In other words, they allow for the modeling of temporal reciprocities, such as affordances, that set up the conditions for their own continuation.

\section{An eye on the world at large}

The above methods naturally favor the quantifiable. That is, they select those aspects of ambient patterns that are relatively invariant across circumstances or the dynamics that are reliably reproduced or captured by relatively simple equations. Such a focus makes sense from an experimental point of view: Precarious and indeterminate features of the world are much harder to, well, determine. But that, I have argued, is no reason to exclude them from our considerations (Costall, 2004; Dewey, 1958; Van Dijk, 2020). An important implication going forward is that ecological psychology, and psychology in general, cannot afford losing track of the indeterminate aspects of the shared world.

Psychological scientists should expand not only the scope of their own methods but also the techniques they use. Fields such as anthropology and ethnography come with methods that are mindful of the world at large (e.g., Harris, Keil, Sutton, Barnier, \& McIlwain, 2011; Hutchins, 1995; Ingold, 2011, 2018; Lave, 1988; Malafouris, 2013; Mol, 2002; Suchman, 2007). Ethnographical methods may not readily quantify the shared world, but they do allow researchers to attend to activities that unfold over longer timescales.

If we take the world to be constitutive of human experience, as ecological psychology urges, these fields may supply psychology with new ways of approaching old problems. Van Dijk and Rietveld (2018), for 
example, studied the temporal structure of the affording world of architects to understand how the activities of architects working together, across timescales, allowed them to envision an architectural installation that has yet to be built. That is, they aimed to account for long-term planning, not, as has traditionally been done, by explaining such planning in terms of mental models or representations but rather by studying the inviting, material world that unfolds across longer timescales as people participate in them (see also Stepp \& Turvey, 2010).

Finally, however, human participation in the world does not just organize us; it also organizes what other animals can do. Being invited to a grocery store to buy beef codetermines the way materials across the globe are organized to set up the conditions in the grocery store to continue that very organization. This is not limited to the configuration of the shelves or the roof of the building. It also includes production lines for processing cattle, the layout of the grocery store, the things that cattle farmers need to do each day, and so on. Habitually eating beef spills into the possibility of life for other species. In an affording world, as argued above, humans are responsible for the world they share with other animals. Any activity we develop will change the possibility for the activities of other animals that codetermine their world with ours.

If we are serious about understanding what "the head is inside of," psychology benefits from collaborations with fields that make worldly responsibility visible and show worldly connections across generations or species that psychology currently is not registering (e.g., Tsing, 2015; Van Dooren, 2014). It calls for crossing disciplinary bounds to find ways of thematizing indeterminacy and worldly precariousness. The temporal view of affordances thus calls for questions of what materials set up the condition to invite a particular activity and, conversely, what material organization is continued by responding to a particular way of acting.

What this means is that taking responsibility is afforded. It is afforded, that is, if we take care of the material organization of the world in such a way that it invites questions about our own involvement. We can try to promote a world that lets us be organized by intergenerational practices of storytelling, of reading about other people and animals, and so on-just as a physician can be organized by mathematical practices to look at a patient. In so doing, one can experience a real, worldly tension in being invited to buy beef while thus contributing, in a small degree, to the working conditions of farmers or to the loss of the habitats of vultures.

\section{Concluding Remarks}

By placing the ecological approach within the context of evolutionary theory and its pragmatist roots, this article shows that the ecological approach allows psychology to focus its attention on the precariousness of the shared world. The temporalized notion of affordance developed in this article has suggested an active relation to the world whereby animals experience the world as they extend their activities further and further into it. Conceiving of the world as codetermined in action may help psychology to foreground the responsibilities that come with the place humans have taken up in the world and the space we hold open for other animals.

This is not to say that determining responsibility is easy. It is, for example, far from clear whether the farmers in India should or should not treat their cattle with diclofenac. Painkillers have become widely used in industrial farming. Diclofenac is no doubt readily available to the farmers in India for this reason. But these farmers are not directly part of this material organization. Their use of painkillers is primarily driven by poverty (Van Dooren, 2014, pp. 53-54). Diclofenac affords the farmers a way of keeping their cattle going for as long as they can. Responsibilities are diffuse, conflicting, and may be difficult if not impossible to determine. But that, I have argued, does not make them less part of the world.

An affording world is unfinished, as I have stressed throughout this article. It invites activity to keep it going in one direction rather than another. That does not mean that anything is possible. It does mean, however, that although human activities are implicated in a massive loss of habitats, increased extinction rates, climate change, and so on, they could also change the world for the better by trying to develop the material organizations that make the precarious goods more stable and keep risk at bay (Dewey, 1958, p. 77). As Dewey intimated, responsibility in a determining world is not a matter of personal choice, to take it or leave it as we please. Responsibility is afforded. It requires working together in developing and maintaining the material organizations that invite questions about our own involvement: worldly practices of storytelling, education, science, and art. Our attempts at answering the questions these practices raise can concurrently improve the ways we share the world.

Psychology has a responsibility in this respect. The way psychology teaches us to conceive of the world, and our relation to it, has consequences for the role we take ourselves to occupy in the world (Costall, 1995; Danziger, 1990, 1997; Louch, 1966). Perspectives that put materially organized activity inside the head, from experiencing a flame or making inferences to feeling responsible for the lives of vultures, systematically shift our attention away from the world at large-away from the very same indeterminate world that may yet afford us ways of improving it. Such a view of psychology risks relegating human responsibility because it propagates 
an old view that we may depend on the world for our life, but the world never came to depend on us for its existence. An open-ended view of affordances can remind us that existence is not finished and that we may yet find ways of changing it for the better.

\section{Transparency}

Action Editor: Laura A. King

Editor: Laura A. King

Declaration of Conflicting Interests

The author(s) declared that there were no conflicts of interest with respect to the authorship or the publication of this article.

Funding

This research was supported by Research Foundation Flanders (FWO) Grant 12V2318N (project "Thinking in practice: a unified ecological-enactive account").

\section{ORCID iD}

Ludger van Dijk (D) https://orcid.org/0000-0002-8681-1722

\section{Acknowledgments}

I am grateful to Jelle Bruineberg and to Erik Myin and Victor Loughlin for their thoughts and helpful suggestions. I am also indebted to Harry Heft, Erik Rietveld, and Julian Kiverstein for sharing their thoughts on an earlier version of this article. I thank the two anonymous reviewers for their constructive criticism.

\section{References}

Adolph, K. E., Eppler, M. A., \& Gibson, E. J. (1993). Crawling versus walking infants' perception of affordances for locomotion over sloping surfaces. Child Development, 64 , 1158-1174. doi:10.1111/j.1467-8624.1993.tb04193.x

Anderson, M. (2014). After phrenology: Neural reuse and the interactive brain. Cambridge, MA: MIT Press.

Baggs, E., \& Chemero, A. (2018). Radical embodiment in two directions. Synthese. Advance online publication. doi:10.1007/s11229-018-02020-9

Barker, R. G. (1968). Ecological psychology: Concepts and methods for studying the environment of human behavior. Stanford, CA: Stanford University Press.

Barrett, L. (2011). Beyond the brain: How body and environment shape animal and buman minds. Princeton, NJ: Princeton University Press.

Ben-Zeev, A. (1984). The Kantian revolution in perception. Journal for the Theory of Social Behaviour, 14(1), 69-84. doi:10.1111/j.1468-5914.1984.tb00488.x

Bruineberg, J., Kiverstein, J., \& Rietveld, E. (2018). The anticipating brain is not a scientist: The free-energy principle from an ecological-enactive perspective. Synthese, 195, 2417-2444. doi:10.1007/s11229-016-1239-1

Brush, J. E., Lee, M., Sherbino, J., Taylor-Fishwick, J. C., \& Norman, G. (2019). Effect of teaching Bayesian methods using learning by concept vs learning by example on medical students' ability to estimate probability of a diagnosis: A randomized clinical trial. JAMA Network Open, 2(12), Article e1918023. doi:10.1001/jamanetworkopen.2019.18023

Carello, C., Grosofsky, A., Reichel, F. D., Solomon, H. Y., \& Turvey, M. T. (1989). Visually perceiving what is reachable. Ecological Psychology, 1(1), 27-54. doi:10.1207/ s15326969eco0101_3

Casscells, W., Schoenberger, A., \& Graboys, T. B. (1978). Interpretation by physicians of clinical laboratory results. New England Journal of Medicine, 299, 999-1001. doi:10.1056/NEJM197811022991808

Chemero, A. (2003). An outline of a theory of affordances. Ecological Psychology, 15, 181-195. doi:10.1207/S1532 6969ECO1502_5

Chemero, A. (2009). Radical embodied cognitive science. Cambridge, MA: MIT Press.

Clark, A. (2016). Surfing uncertainty: Prediction, action, and the embodied mind. Oxford, England: Oxford University Press.

Costall, A. (1995). Socializing affordances. Theory \& Psychology, 5, 467-481. doi:10.1177/0959354395054001

Costall, A. (1997). The meaning of things. Social Analysis, 41(1), 76-85.

Costall, A. (1999). An iconoclast's triptych: Edward Reed's ecological philosophy. Theory \& Psychology, 9, 411-416. doi:10.1177/0959354399093011

Costall, A. (2004). From Darwin to Watson (and cognitivism) and back again: The principle of animal-environment mutuality. Behavior and Philosophy, 32, 179-195.

Courville, A. C., Daw, N. D., \& Touretzky, D. S. (2006). Bayesian theories of conditioning in a changing world. Trends in Cognitive Sciences, 10, 294-300. doi:10.1016/j .tics.2006.05.004

Cowley, S. J. (2011). Taking a language stance. Ecological Psychology, 23, 185-209. doi:10.1080/10407413.2011.59 1272

Cuijpers, L. S., Den Hartigh, R. J., Zaal, F. T., \& de Poel, H. J. (2019). Rowing together: Interpersonal coordination dynamics with and without mechanical coupling. Human Movement Science, 64, 38-46. doi:10.1016/j .humov.2018.12.008

Danziger, K. (1990). Constructing the subject. Cambridge, England: Cambridge University press.

Danziger, K. (1997). Naming the mind. London, England: Sage.

Dent-Read, C., \& Zukow-Goldring, P. (1997). Evolving explanations of development: Ecological approaches to organism-environment systems. Washington, DC: American Psychological Association.

Dewey, J. (1896). The reflex arc concept in psychology. The Psychological Review, 3, 357-370. doi:10.1037/h0070405

Dewey, J. (1910/2009). The influence of Darwin on philosophy. In M. Ruse (Ed.), Philosophy after Darwin (pp. 5561). Princeton, NJ: Princeton University Press. (Original work published 1910)

Dewey, J. (1915). The subject-matter of metaphysical inquiry. The Journal of Philosophy, Psychology and Scientific Methods, 12, 337-345. doi:10.2307/2013770

Dewey, J. (1958). Experience and nature. New York, NY: Dover Publications. 
De Wit, M., de Vries, S., van der Kamp, J., \& Withagen, R. (2017). Affordances and neuroscience: Steps towards a successful marriage. Neuroscience \& Biobehavioral Reviews, 80, 622-629. doi:10.1016/j.neubiorev.2017.07.008

De Wit, M. M., \& Withagen, R. (2019). What should a "Gibsonian neuroscience" look like? Introduction to the special issue. Ecological Psychology, 31, 147-151. doi:10 .1080/10407413.2019.1615203

Dreyfus, H. L., \& Kelly, S. D. (2007). Heterophenomenology: Heavy-handed sleight-of-hand. Phenomenology and the Cognitive Sciences, 6, 45-55. doi:10.1007/s11097-0069042-y

Dutilh Novaes, C. (2013). A dialogical account of deductive reasoning as a case for how culture shapes cognition. Journal of Cognition and Culture, 13, 459-482. doi:10.1163/15685373-12342104

Fajen, B. R. (2007). Affordance-based control of visually guided action. Ecological Psychology, 19, 383-410. doi:10 .1080/10407410701557877

Franchak, J., \& Adolph, K. (2007). Perceiving changing affordances for action: Pregnant women walking through doorways. Journal of Vision, 7, 116. doi:10.1167/7.9.116

Friston, K. (2009). The free-energy principle: A rough guide to the brain? Trends in Cognitive Sciences, 13, 293-301. doi:10.1016/j.tics.2009.04.005

Gallagher, S. (2017). Enactivist interventions: Rethinking the mind. Oxford, England: Oxford University Press.

Gaver, W. W. (1993). How do we hear in the world? Explorations in ecological acoustics. Ecological Psychology, 5, 285-313. doi:10.1207/s15326969eco0504_2

Gibson, J. J. (1966). The senses considered as perceptual systems. Boston, MA: Houghton Mifflin Harcourt.

Gibson, J. J. (1979). The ecological approach to visual perception. Boston, MA: Houghton Mifflin Harcourt.

Gordon, M. S., \& Rosenblum, L. D. (2004). Perception of sound-obstructing surfaces using body-scaled judgments. Ecological Psychology, 16, 87-113. doi:10.1207/ s15326969eco1602_1

Green, R. E., Newton, I. A. N., Shultz, S., Cunningham, A. A., Gilbert, M., Pain, D. J., \& Prakash, V. (2004). Diclofenac poisoning as a cause of vulture population declines across the Indian subcontinent. Journal of Applied Ecology, 41, 793-800. doi:10.1111/j.0021-8901.2004.00954.x

Harris, C. B., Keil, P. G., Sutton, J., Barnier, A. J., \& McIlwain, D. J. (2011). We remember, we forget: Collaborative remembering in older couples. Discourse Processes, 48 , 4267-4303. doi:10.1080/0163853X.2010.541854

Heft, H. (1989). Affordances and the body: An intentional analysis of Gibson's ecological approach to visual perception. Journal for the Theory of Social Behaviour, 19, 1-30. doi:10.1111/j.1468-5914.1989.tb00133.x

Heft, H. (2001). Ecological psychology in context: James Gibson, Roger Barker, and the legacy of William James's radical empiricism. Mahwah, NJ: Erlbaum.

Heft, H. (2007). The social constitution of perceiver-environment reciprocity. Ecological Psychology, 19, 85-105. doi:10.1080/10407410701331934

Heras-Escribano, M. (2019). Pragmatism, enactivism, and ecological psychology: Towards a unified approach to post-cognitivism. Synthese. Advance online publication. doi:10.1007/s11229-019-02111-1

Hodges, B. H., \& Baron, R. M. (1992). Values as constraints on affordances: Perceiving and acting properly. Journal for the Theory of Social Behaviour, 22, 263-294. doi:10.1111/j.1468-5914.1992.tb00220.x

Hodges, B. H., \& Lindhiem, O. (2006). Carrying babies and groceries: The effect of moral and social weight on caring. Ecological Psychology, 18, 93-111. doi:10.1207/s153 26969eco1802_2

Houston, D. C., \& Cooper, J. E. (1975). The digestive tract of the whiteback griffon vulture and its role in disease transmission among wild ungulates. Journal of Wildlife Diseases, 11, 306-313. doi:10.7589/0090-3558-11.3.306

Hutchins, E. (1995). Cognition in the wild. Cambridge, MA: MIT Press.

Ingold, T. (2011). Being alive: Essays on movement, knowledge and description. Abingdon, England: Routledge.

Ingold, T. (2015). The life of lines. Abingdon, England: Routledge.

Ingold, T. (2018). Anthropology and/as education. Abingdon, England: Routledge.

James, W. (1912). Essays in radical empiricism. Mineola, NY: Dover Publications.

Keijzer, F., Van Duijn, M., \& Lyon, P. (2013). What nervous systems do: Early evolution, input-output, and the skin brain thesis. Adaptive Behavior, 21(2), 67-85. doi:10 $.1177 / 1059712312465330$

Kelso, J. A. S. (1995). Dynamic patterns: The self-organization of brain and behavior. Cambridge, MA: MIT Press.

Kirchhoff, M. (2015). Extended cognition and the causalconstitutive fallacy: In search for a diachronic and dynamical conception of constitution. Philosophy and Phenomenological Research, 90, 320-360. doi:10.1111/ phpr.12039

Kugler, P. N., \& Turvey, M. T. (1987). Information, natural law, and the self-assembly of rhythmic movement. Hillsdale, NJ: Erlbaum.

Lave, J. (1988). Cognition in practice: Mind, mathematics and culture in everyday life. New York, NY: Cambridge University Press.

Lee, D. N., \& Reddish, P. E. (1981). Plummeting gannets: A paradigm of ecological optics. Nature, 293, 293-294.

Lobo, L., Travieso, D., Jacobs, D. M., Rodger, M., \& Craig, C. M. (2018). Sensory substitution: Using a vibrotactile device to orient and walk to targets. Journal of Experimental Psychology: Applied, 24, 108-124. doi:10.1037/xap00 00154

Louch, A. R. (1966). Explanation and human action. Berkeley: University of California Press.

Ma, W. J. (2012). Organizing probabilistic models of perception. Trends in Cognitive Sciences, 16, 511-518. doi:10.1016/j.tics.2012.08.010

Mace, W. M. (1977). James J. Gibson's strategy for perceiving: Ask not what's inside your head, but what your head's inside of. In R. Shaw \& J. Brandsford (Eds.), Perceiving, acting, and knowing (pp. 43-65). Hillsdale, NJ: Erlbaum.

Malafouris, L. (2013). How things shape the mind. Cambridge, MA: MIT Press. 
Mark, L. S. (1987). Eyeheight-scaled information about affordances: A study of sitting and stair climbing. Journal of Experimental Psychology: Human Perception and Performance, 13, 361-370. doi:10.1037/0096-1523.13.3.361

Mead, G. H. (1912). The mechanism of social consciousness. The Journal of Philosophy, Psychology and Scientific Methods, 9, 401-406. doi:10.2307/2012643

Michaels, C. F., \& Carello, C. (1981). Direct perception. Englewood Cliffs, NJ: Prentice-Hall.

Mol, A. (2002). The body multiple: Ontology in medical practice. Durham, NC: Duke University Press.

Myin, E. (2016). Perception as something we do. Journal of Consciousness Studies, 23, 80-104.

Noble, W. G. (1981). Gibsonian theory and the pragmatist perspective. Journal for the Theory of Social Behaviour, 11, 65-85. doi:10.1111/j.1468-5914.1981.tb00023.x

Nomikou, I., Leonardi, G., Radkowska, A., RacczaszekLeonardi, J., \& Rohlfing, K. J. (2017). Taking up an active role: emerging participation in early mother-infant interaction during peekaboo routines. Frontiers in Psychology, 8, 1656. doi:10.3389/fpsyg.2017.01656

Oyama, S. (2000). Evolution's eye: A systems view of the biology-culture divide. Durham, NC: Duke University Press.

Postma, D. B., Lemmink, K. A., \& Zaal, F. T. (2018). The affordance of catchability in running to intercept fly balls. Journal of Experimental Psychology: Human Perception and Performance, 44(9), 1336-1347. doi:10.1037/xhp00 00531

Reed, E. S. (1996). Encountering the world: Toward an ecological psychology. New York, NY: Oxford University Press.

Richardson, D. C., Dale, R., \& Kirkham, N. Z. (2007). The art of conversation is coordination. Psychological Science, 18, 407-413. doi:10.1111/j.1467-9280.2007.01914.x

Richardson, M., Marsh, K., \& Baron, R. (2007). Judging and actualizing intrapersonal and interpersonal affordances. Journal of Experimental Psychology: Human Perception and Performance, 33, 845-859. doi:10.1037/0096-1523 .33 .4 .845

Rietveld, E. S. (2008). Situated normativity: The normative aspect of embodied cognition in unreflective action. Mind, 117, 973-1001. doi:10.1093/mind/fzn050

Rietveld, E. S., \& Kiverstein, J. (2014). A rich landscape of affordances. Ecological Psychology, 26, 325-352. doi:10 $.1080 / 10407413.2014 .958035$

Schmidt, R. C., \& Richardson, M. J. (2008). Dynamics of interpersonal coordination. In A. Fuchs \& V.K. Jirsa (Eds.), Coordination: Neural, behavioral and social dynamics (pp. 281-308). Berlin, Germany: Springer.

Seifert, L., Wattebled, L., Hérault, R., Poizat, G., Adé, D., Gal-Petitfaux, N., \& Davids, K. (2014). Neurobiological degeneracy and affordance perception support functional intra-individual variability of inter-limb coordination during ice climbing. PLOS ONE, 9(2), Article e89865. doi:10.1371/journal.pone.0089865

Shaw, R., \& Turvey, M. (1981). Coalitions as models of ecosystems: A realist perspective on perceptual organization. In M. Kubovy \& J. R. Pomerantz (Eds.), Perceptual organization (pp. 343-415). Hillsdale, NJ: Erlbaum.

Shotter, J. (1983). "Duality of structure" and "intentionality" in an ecological psychology. Journal for the Theory of Social
Behaviour, 13, 19-44. doi:10.1111/j.1468-5914.1983. tb00460.x

Silberstein, M., \& Chemero, A. (2013). Constraints on localization and decomposition as explanatory strategies in the biological sciences. Philosophy of Science, 80, 958-970. doi:10.1086/674533

Stepp, N., \& Turvey, M. T. (2010). On strong anticipation. Cognitive Systems Research, 11, 148-164. doi:10.1016/j .cogsys.2009.03.003

Stoffregen, T. A. (2003). Affordances as properties of the animal-environment system. Ecological Psychology, 15, 115-134. doi:10.1207/S15326969ECO1502_2

Streit, M., Shockley, K., \& Riley, M. A. (2007). Rotational inertia and multimodal heaviness perception. Psychonomic Bulletin \& Review, 14, 1001-1006. doi:10.3758/BF03194135

Suchman, L. A. (2007). Human-machine reconfigurations: Plans and situated actions. Cambridge, England: Cambridge University Press.

Szokolszky, A., \& Read, C. (2018). Developmental ecological psychology and a coalition of ecological-relational developmental approaches. Ecological Psychology, 30(1), 6-38. doi:10.1080/10407413.2018.1410409

Tsing, A. (2015). The mushroom at the end of the world: On the possibility of life in capitalist ruins. Princeton, NJ: Princeton University Press.

Turvey, M. T. (1990). Coordination. American Psychologist, 45, 938-953. doi:10.1037/0003-066X.45.8.938

Turvey, M. T. (1992). Affordances and prospective control: An outline of the ontology. Ecological Psychology, 4, 173-187. http://dx.doi.org/10.1207/s15326969eco0403_3

Turvey, M. T. (1996). Dynamic touch. American Psychologist, 51, 1134-1152. doi:10.1037/0003-066X.51.11.1134

Turvey, M. T. (2019). Lectures on perception: An ecological perspective. New York, NY: Routledge.

Turvey, M. T., \& Shaw, R. E. (1999). Ecological foundations of cognition. I: Symmetry and specificity of animalenvironment systems. Journal of Consciousness Studies, 6, 95-110.

Van den Herik, J. C. (2018). Attentional actions-an ecological-enactive account of utterances of concrete words. Psychology of Language and Communication, 22(1), 90-123.

Van Dijk, L. (2020). Temporalizing ontology: a case for pragmatic emergence. Synthese. Advance online publication. doi:10.1007/s11229-020-02615-1

Van Dijk, L., \& Kiverstein, J. (2020). Direct perception in context: Radical empiricist reflections on the medium. Synthese. Advance online publication. doi:10.1007/s11 229-020-02578-3

Van Dijk, L., \& Rietveld, E. (2018). Situated anticipation. Synthese. Advance online publication. doi:10.1007/ s11229-018-02013-8

Van Dooren, T. (2014). Flight ways: Life and loss at the edge of extinction. New York, NY: Columbia University Press.

Van Orden, G. C., Holden, J. G., \& Turvey, M. T. (2003). Self-organization of cognitive performance. Journal of Experimental Psychology: General, 132, 331-350. doi:10.1037/0096-3445.132.3.331

Von Helmholtz, H. (1878). Epistemological writings. Dordrecht, The Netherlands: D. Reidel Publishing Company. 
Warren, W. H. (1984). Perceiving affordances: Visual guidance of stair climbing. Journal of Experimental Psychology: Human Perception and Performance, 10, 683-703. doi:10.1037/0096-1523.10.5.683

Warren, W. H. (2006). The dynamics of perception and action. Psychological Review, 113, 358-389. doi:10.1037/0033295X.113.2.358

Warren, W. H. (2018). Collective motion in human crowds. Current Directions in Psychological Science, 27, 232-240. doi:10.1177/0963721417746743

Warren, W. H., Kay, B. A., Zosh, W. D., Duchon, A. P., \& Sahuc, S. (2001). Optic flow is used to control human walking. Nature Neuroscience, 4, 213-216. doi:10.1038/ 84054

Withagen, R., \& Chemero, A. (2009). Naturalizing perception developing the Gibsonian approach to perception along evolutionary lines. Theory \& Psychology, 19, 363-389. doi:10.1177/0959354309104159
Withagen, R., De Poel, H. J., Araújo, D., \& Pepping, G. (2012). Affordances can invite behavior: Reconsidering the relationship between affordances and agency. New Ideas in Psychology, 30, 250-258. doi:10.1016/j.newidea psych.2011.12.003

Withagen, R., \& Van der Kamp, J. (2010). Towards a new ecological conception of perceptual information: Lessons from a developmental systems perspective. Human Movement Science, 29, 149-163. doi:10.1016/j.humov.2009.09.003

Withagen, R., \& Van Wermeskerken, M. (2009). Individual differences in learning to perceive length by dynamic touch: Evidence for variation in perceptual learning capacities. Perception E Psychophysics, 71(1), 64-75. doi:10.3758/ APP.71.1.64

Zahidi, K., \& Myin, E. (2016). Radically enactive numerical cognition. In G. Etzelmüller \& C. Tewes (Eds.), Embodiment in evolution and culture (pp. 57-72). Tübingen, Germany: Mohr-Siebich. 